ORIGINAL ARTICLE

Wataru Obara $\cdot$ Aritoshi Iida $\cdot$ Yasushi Suzuki

Toshihiro Tanaka $\cdot$ Fumihiro Akiyama $\cdot$ Shiro Maeda

Yozo Ohnishi · Ryo Yamada - Tatsuhiko Tsunoda

Takashi Takei · Kyoko Ito · Kazuho Honda

Keiko Uchida · Ken Tsuchiya · Wako Yumura

Takashi Ujiie · Yutaka Nagane · Kosaku Nitta

Satoru Miyano · Ichiei Narita · Fumitake Gejyo

Hiroshi Nihei · Tomoaki Fujioka $\cdot$ Yusuke Nakamura

\title{
Association of single-nucleotide polymorphisms in the polymeric immunoglobulin receptor gene with immunoglobulin A nephropathy (IgAN) in Japanese patients
}

Received: 20 February 2003/ Accepted: 1 April 2003/Published online: 10 May 2003

(C) The Japan Society of Human Genetics and Springer-Verlag 2003

\begin{abstract}
Immunoglobulin A nephropathy (IgAN) is a primary glomerulonephritis of common incidence world-wide whose etiology and pathogenesis remain unresolved, although genetic factors are assumed to be involved in the development and progression of this disease. To identify genetic variations that might confer susceptibility to IgAN, we performed a case-control association study involving 389 Japanese IgAN patients and 465 controls. Genome-wide analysis of approximately 80,000 single-nucleotide polymorphisms (SNPs)
\end{abstract}

Electronic database information: URLs for the data in this article are as follows: Online Mendelian Inheritance in Man (for IgAN, MIM161950): http://www.ncbi.nlm.nih.gov/Omim/JSNP (for SNPs and primers): http://snp.ims.u-tokyo.ac.jp/

W. Obara $\cdot$ F. Akiyama $\cdot$ S. Miyano $\cdot$ Y. Nakamura Human Genome Center, The Institute of Medical Science, University of Tokyo, Tokyo, Japan

W. Obara · Y. Suzuki · T. Fujioka

Department of Urology, Iwate Medical University,

Iwate, Japan

A. Iida

Laboratory for Genotyping, SNP Research Center,

The Institute of Physical and Chemical Research (RIKEN),

Tokyo, Japan

T. Tanaka $\cdot$ Y. Ohnishi

Laboratory for Cardiovascular Diseases, SNP Research Center,

The Institute of Physical and Chemical Research (RIKEN),

Tokyo, Japan

S. Maeda

Laboratory for Diabetic Nephropathy, SNP Research Center,

The Institute of Physical and Chemical Research (RIKEN),

Tokyo, Japan

R. Yamada

Laboratory for Rheumatic Diseases, SNP Research Center,

The Institute of Physical and Chemical Research (RIKEN),

Tokyo, Japan identified a significant association between $\operatorname{IgAN}$ and six SNPs located in the PIGR (polymeric immuoglobulin receptor) gene at chromosome 1q31-q41. One of them, PIGR-17, caused an amino-acid substitution from alanine to valine at codon $580 \quad\left(\chi^{2}=13.05\right.$, $P=0.0003$, odds ratio $[\mathrm{OR}]=1.59,95 \%$ confidence interval $[95 \% \mathrm{CI}]=1.24-2.05)$; the $\mathrm{OR}$ of minor homozygotes to others was $2.71(95 \% \mathrm{CI}=1.31-5.61)$. Another SNP, PIGR-2, could affect promoter activity $\left(\chi^{2}=11.95, \quad P=0.00055, \quad \mathrm{OR}=1.60,95 \% \quad \mathrm{CI}=1.22\right.$

T. Tsunoda

Laboratory for Medical Informatics, SNP Research Center,

The Institute of Physical and Chemical Research (RIKEN),

Tokyo, Japan

T. Takei $\cdot \mathrm{K}$. Ito $\cdot \mathrm{K}$. Honda $\cdot \mathrm{K}$. Uchida $\cdot \mathrm{K}$. Tsuchiya

W. Yumura $\cdot$ K. Nitta $\cdot$ H. Nihei

Department of Medicine, Kidney Center,

Tokyo Women's Medical University, Tokyo, Japan

T. Ujiie

Department of Urology,

Iwate Prefectural Ofunato Hospital,

Iwate, Japan

Y. Nagane

Department of Urology, Sanai Hospital, Iwate, Japan

I. Narita $\cdot$ F. Gejyo

Division of Clinical Nephrology and Rheumatology,

Niigata University Graduate School of Medical

and Dental Sciences, Niigata, Japan

Y. Nakamura $(\square)$

Laboratory of Molecular Medicine,

Human Genome Center, Institute of Medical Science,

University of Tokyo,

4-6-1 Shirokanedai, Minato-ku,

Tokyo 108-8639, Japan

E-mail: yusuke@ims.u-tokyo.ac.jp

Tel.: + 81-3-54495372

Fax: + 81-3-54495433 
2.08); the OR of minor homozygotes to others was 2.08 $(95 \% \mathrm{CI}=0.94-4.60)$. Pairwise analyses demonstrated that all six SNPs were in almost complete linkage disequilibrium. Biopsy specimens from IgAN patients were positively stained by antibody against the secretory component of PIGR, but corresponding tissues from non-IgAN patients were not. Our results suggest that a gene associated with susceptibility to IgAN lies within or close to the PIGR gene locus on chromosome 1q in the Japanese population.

Keywords Single-nucleotide polymorphism .

$\operatorname{IgA}$ nephropathy $\cdot$ Polymeric immunoglobulin receptor

\section{Introduction}

Immunoglobulin A nephropathy (IgAN; MIM161950), characterized by the deposition of immunoglobulin $\mathrm{A}$ at the mesangium of glomeruli (Berger and Hinglasis 1968) is the most common form of glomerulonephritis worldwide and is a major cause of end-stage renal disease. Surveys of patients with primary glomerulonephritis conducted in 1985 and 1993 by the Research Group on Progressive Renal Diseases in Japan revealed a high prevalence of IgAN and relatively poor prognosis for patients (Koyama et al. 1997). The rate of survival for the 502 cases of IgAN followed in that study, for which renal-related death was the end-point, was $61 \%$ at 20 years from the time when renal dysfunction was first detected. Strong evidence of a role for genetic factors in the development and progression of IgAN has come from descriptive reports of familial aggregation and from analyses of affected sib-pairs and parent-child pairs from multiple ethnic groups (Hsu et al. 2000). Sporadic IgAN is difficult to evaluate, however, because it probably involves a combination of various genes and diverse environmental factors (Schena 1998). We chose therefore to look for potential IgAN-susceptibility genes that might correlate with the development and/or progression of this disease.

Polymeric immunoglobulin receptor (PIGR) is an integral membrane protein on the basolateral surface of secretory epithelial cells. It mediates the transport of polymeric immunoglobulins ( $\mathrm{pIg}$ ) across epithelia, particularly dimeric IgA or polymeric IgM (Brandtzaeg and Prydz 1984). Expression of PIGR mRNA can be detected in most human secretory epithelia, e.g., in the intestine, bronchus, salivary glands, renal tubule, and uterus (Krajci et al. 1989). PIGR neutralizes extracellular and intracellular pathogens in mucous membranes by transporting dimeric IgA-pathogen complexes across epithelia and then excreting them via epithelial transcytosis by means of a domain known as the secretory component (SC), although the restriction site of PIGR that binds to the pIg-pathogen is not clarified completely (Mostov et al. 1984). PIGR-knockout mice develop increased levels of serum IgA because of the interruption of the trans-epithelial transport of dimeric IgA (Shimada et al. 1999). On the basis of these findings, one may ascribe the primary abnormalities of IgAN to the impairment of PIGR-mediated transport of IgA; therefore, PIGR represents a potential candidate for the mediation of IgA binding to mesangial cells.

Recent approaches to the discovery of disease-susceptibility genes have focused on the identification of single-nucleotide polymorphisms (SNPs) in the human genome. SNPs are likely to be useful for the identification of genes involved in complex diseases through association studies and, as such, serve as markers for various genetic analyses (Kruglyak 1999). Because SNPs are the most frequent type of genetic variation in human DNA, we have screened gene-based SNPs on a genomewide scale to detect possible associations with susceptibility to $\operatorname{IgAN}$. Earlier, we reported a case-control association study that identified SNPs in the L- and E-selectin genes on chromosome 1q24-25 as potential susceptibility factors for IgAN in the Japanese population (Takei et al. 2002). Furthermore, we reported that the HLA-DRA locus on chromosome $6 p$ was a susceptibility gene for IgAN in the Japanese population (Akiyama et al. 2002). For the present work, we designed a case-control association study with approximately 80,000 SNPs found on genome-wide scans and estimated haplotypes that might serve to identify SNPs on chromosome 1q31-q41 that might be responsible for IgAN phenotypes in the Japanese population.

\section{Materials and methods}

\section{Materials}

IgAN in our study population was diagnosed by renal biopsy as a mesangial proliferative glomerulonephritis with predominant IgA and $\mathrm{C} 3$ depositions in the mesangium. All biopsies were performed after 1976 at the following surgical centers in Japan: Department of Urology, Iwate Medical University; Department of Urology, Sanai Hospital; Department of Urology, Iwate Prefectural Ofunato Hospital; Department of Medicine, Kidney Center, Tokyo Women's Medical University; Division of Clinical Nephrology and Rheumatology, Niigata University Graduate School of Medical and Dental Sciences. Patients with HenochSchonlein purpura or secondary IgAN as liver cirrhosis were excluded from analysis. Peripheral blood samples were obtained from 389 IgAN patients (222 females and 167 males, mean age: $38.5 \pm 14.4$ years) for extraction of DNA. The mean value of serum creatinine at the time of renal biopsy was $0.98 \pm 0.33 \mathrm{mg} / \mathrm{dl}$; the mean value of 24-h proteinuria at the time of renal biopsy was $0.89 \pm 1.01 \mathrm{~g} /$ day. As controls, we analyzed DNA from 465 healthy Japanese volunteers (278 females and 187 males, mean age: $54.4 \pm 14.5$ years). These controls were randomly selected; none showed hematuria, proteinuria, or renal dysfunction. Written informed consent was obtained from all participants, and DNA was prepared from each blood sample according to standard protocols.

\section{Screening of SNPs}

SNPs in $P I G R$ gene were screened according to methods described previously (Iida et al. 2001). Information about each SNP that we 
have discovered can be obtained from the Japanese SNP Web site (JSNP) at http://snp.ims.u-tokyo.ac.jp/.

\section{Multiplexed polymerase chain reaction}

We amplified multiple genomic fragments by using $20 \mathrm{ng}$ genomic DNA for each polymerase chain reaction (PCR), as described previously (Ohnishi et al. 2001). Sequences of the primers used in this study are available at JSNP (http://snp.ims.u-tokyo.ac.jp/). Each PCR was performed in a $20-\mu$ l solution containing $50 \mathrm{pmol}$ each primer, $10 \mathrm{U}$ Ex-Taq DNA polymerase (TaKaRa Shuzo, Tokyo, Japan), and $0.55 \mu \mathrm{g}$ TaqStart (Clontech Laboratories, Palo Alto, Calif., USA) in a GeneAmp PCR system 9700 (PE Applied Biosystems). Initial denaturation was at $94^{\circ} \mathrm{C}$ for $2 \mathrm{~min}$, followed by 37 cycles of amplification at $94^{\circ} \mathrm{C}$ for $15 \mathrm{~s}$ and annealing at $60^{\circ} \mathrm{C}$ for $45 \mathrm{~s}$, with final extension for $2 \mathrm{~min}$ at $72^{\circ} \mathrm{C}$.

\section{Genotyping}

We genotyped all participants for a total of 21 SNPs present in the $P I G R$ gene (PIGR 1-21; Fig. 1) by means of the Invader assay, which combines a structure-specific cleavage enzyme with a universal fluorescent resonance energy transfer (FRET) system (Mein et al. 2000). FRET probes were labeled with either FAM or VIC corresponding to each allele. Signal intensity was indicated as the ratio of FAM or VIC to ROX, an internal reference. Each total reaction volume of $5 \mu \mathrm{l}$ contained $0.25 \mu \mathrm{l}$ signal buffer, $0.25 \mu \mathrm{l}$ each FRET probe, $0.25 \mu \mathrm{l}$ structure-specific cleavage enzyme, $0.5 \mu \mathrm{l}$ allele-specific probe mix, and $2 \mu \mathrm{l}$ PCR product diluted 1:10. Samples were incubated in a GeneAmp PCR system $9700\left(95^{\circ} \mathrm{C}\right.$ for $5 \mathrm{~min}$ and then at $63^{\circ} \mathrm{C}$ for $15 \mathrm{~min}$ ) and were analyzed on an $\mathrm{ABI}$ Prism 7700 sequence detector.

\section{Immunohistochemistry for SC and IgA}

Tissues from renal biopsies were fixed in $10 \%$ formalin, routinely processed, and embedded in paraffin. Paraffin sections ( $3 \mu \mathrm{m}$ thick) were immunostained for SC and IgA. The avidin-biotinylatedperoxidase complex method was performed by using a Histofine SAB-PO KIT (Nichirei, Tokyo, Japan). Briefly, the sections were de-paraffinized in xylene and soaked in absolute methanol containing $0.3 \% \mathrm{H}_{2} \mathrm{O}_{2}$ for 30 min to block endogenous peroxidase activity. After being washed in phosphate-buffered saline for $20 \mathrm{~min}$, the sections were incubated with antibodies overnight. The primary antibodies consisted of rabbit anti-human secretory component (1:200 dilution, DAKO, Glostrup, Denmark) and rabbit anti-IgA (1:50 dilution, Lip Sandon-Lipshow, Detroit, Mich.). The sections were treated with biotinylated anti-rabbit immunoglobulin for $30 \mathrm{~min}$ at room temperature and then allowed to react with peroxidase-labeled avidin for $30 \mathrm{~min}$. All sections were rinsed with
TRIS-buffered saline after each step. After incubation of the sections in $0.05 \mathrm{~mol} / \mathrm{l}$ TRIS-HCl buffer ( $\mathrm{pH} 7.6$ ) containing $0.005 \%$ 3-3-diaminobenzidine, nuclei were stained with hematoxylin.

Statistical analysis

Genotype distributions and allele frequencies of each selected SNP were compared between cases and controls by means of the $\chi^{2}$ test. Significance was judged according to the guidelines of Lander and Kruglyak (1995). Odds ratios (OR) and 95\% confidence intervals $(95 \% \mathrm{CI})$ were calculated by Woolf's method. Hardy-Weinberg equilibrium of alleles at individual loci was assessed by $\chi^{2}$ statistics (Nielsen et al. 1998). Linkage disequilibrium (LD) coefficients were calculated and expressed as $\mathrm{D}^{\prime}=\mathrm{D} /$ Dmax (Devlin and Risch 1995).

\section{Results}

We performed a case-control association study by genotyping approximately 80,000 SNPs scattered throughout the genome. When the $P$-value in the statistical analysis was less than 0.01 , we increased the number of $\operatorname{IgA}$ cases. The distributions of genotypes that we observed in IgAN patients and controls did not differ from the expected frequencies under the assumption of Hardy-Weinberg equilibrium (data not shown). However, comparison of allelic frequencies in IgAN patients versus controls disclosed a significant association of the disease with one SNP present in the PIGR gene (PIGR-17 in exon 7). In view of the strong association found at this locus, we screened for additional SNPs within the PIGR gene.

Among the 20 new SNPs that we discovered within the PIGR gene, we found significant association of five more of them with the IgAN phenotype: PIGR-2 in the $5^{\prime}$ flanking (promoter) region, PIGR-5 in intron 1, PIGR-9 in exon 4, PIGR-13 in intron 4, and PIGR-19 in intron 10 (Table 1). The most significant associations with IgAN at single SNP loci were observed for PIGR-9, PIGR-13, and PIGR-17; these three SNPs were in complete LD. The C-to-T polymorphism of PIGR-17 substitutes valine for alanine at codon 580 of PIGR, and the frequency of the minor allele (T) of PIGR-17 was significantly higher in patients with IgAN than in con-

Fig. 1 Genomic organization of the human polymeric immunoglobulin receptor $(P I G R)$ gene at chromosome 1q31-41 (rectangles exons, horizontal lines introns). Locations of the 21 SNPs identified in this study are indicated above the gene

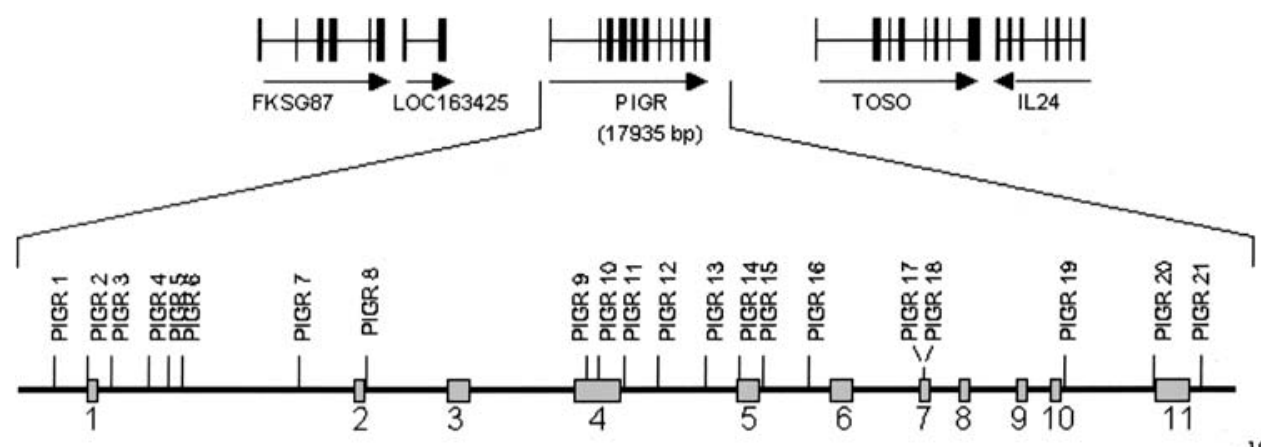


Table 1 Genotype data and association tests of SNPs on the PIGR gene

\begin{tabular}{|c|c|c|c|c|c|c|}
\hline & PIGR-2 & PIGR-5 & PIGR-9 & PIGR-13 & PIGR 17 & PIGR-19 \\
\hline \multicolumn{7}{|l|}{ SNP information } \\
\hline Location & $5^{\prime}$ flanking & Intron 1 & Exon 4 & Intron 4 & Exon 7 & Intron 10 \\
\hline Genetic variation & $\mathrm{G} \rightarrow \mathrm{T}$ & $\mathrm{C} \rightarrow \mathrm{T}$ & $\mathrm{A} \rightarrow \mathrm{G}$ & $\mathrm{T} \rightarrow \mathrm{C}$ & $\mathrm{C} \rightarrow \mathrm{T}$ & $\mathrm{A} \rightarrow \mathrm{G}$ \\
\hline Substitution & & & Val 183 Val & & Ala 580 Val & \\
\hline \multicolumn{7}{|l|}{$\operatorname{IgAN}$} \\
\hline Major homozygous [\%] & $263[67.61]$ & $263[67.61]$ & $252[64.78]$ & $252[64.78]$ & $252[64.78]$ & $256[65.81]$ \\
\hline Heterozygous [\%] & 109 [28.02] & 109 [28.02] & 113 [29.05] & $113[29.05]$ & 113 [29.05] & 111 [28.53] \\
\hline Minor Homozygous [\%] & $17[4.37]$ & $17[4.37]$ & $24[6.17]$ & $24[6.17]$ & $24[6.17]$ & $22[5.66]$ \\
\hline Total & $389[100.00]$ & $389[100.00]$ & $389[100.00]$ & $389[100.00]$ & $389[100.00]$ & $389[100.00]$ \\
\hline \multicolumn{7}{|l|}{ Controls } \\
\hline Major allele [\%] & 815 [87.63] & 815 [87.63] & 799 [85.91] & 799 [85.91] & 799 [85.91] & $802[86.24]$ \\
\hline Total & $465[100.00]$ & $465[100.00]$ & $465[100.00]$ & $465[100.00]$ & $465[100.00]$ & $465[100.00]$ \\
\hline \multicolumn{7}{|l|}{$\chi^{2}[P]$} \\
\hline Genotype frequency $(2 \times 3$ table $)$ & $11.20[0.00369]$ & $11.20[0.00369]$ & $12.73[0.00172]$ & $12.73[0.00172]$ & $12.73[0.00172]$ & $11.60[0.00302]$ \\
\hline Allele frequency (major vs minor) & $11.95[0.00055]$ & $11.95[0.00055]$ & $13.95[0.00030]$ & $13.95[0.00030]$ & $13.95[0.00030]$ & $11.63[0.00065]$ \\
\hline Major homozygous vs others & $10.33[0.00131]$ & $10.33[0.00131]$ & $8.92[0.00282]$ & $8.92[0.00282]$ & $8.92[0.00282]$ & $7.93[0.00487]$ \\
\hline Minor Homozygous vs. Others & $3.41[0.06486]$ & $3.41[0.06486]$ & $7.80[0.00523]$ & $7.80[0.00523]$ & $7.80[0.00523]$ & $7.21[0.00723]$ \\
\hline \multicolumn{7}{|l|}{ Odds ratio $[95 \% \mathrm{Cl}]$ : } \\
\hline Major homozygous vs others & $0.61[0.45-0.82]$ & $0.61[0.45-0.82]$ & $0.64[0.48-0.86]$ & $0.64[0.48-0.86]$ & $0.64[0.48-0.86]$ & $0.65[0.49-0.88]$ \\
\hline Minor homozygous vs others & $2.08[0.94-4.60]$ & $2.08[0.94-4.60]$ & $2.71[1.31-5.61]$ & $2.71[1.31-5.61]$ & $2.71[1.31-5.61]$ & $2.73[1.28-5.83]$ \\
\hline Minor allele vs minor allele & $1.60[1.22-2.08]$ & $1.60[1.22-2.08]$ & $1.59[1.24-2.05]$ & $1.59[1.24-2.05]$ & $1.59[1.24-2.05]$ & $1.56[1.21-2.01]$ \\
\hline
\end{tabular}

Table 2 Linkage disequilibrium (LD) coefficients between 6 SNPs in PIGR gene. LD coefficients were calculated and expressed as $\mathrm{D}^{\prime}=\mathrm{D} /$ Dmax $($ Devlin and Risch 1995)

\begin{tabular}{llllll}
\hline & PIGR-5 & PIGR-9 & PIGR-13 & PIGR 17 & PIGR-19 \\
\hline PIGR-2 & \multirow{2}{*}{1.000} & 0.901 & 0.901 & 0.901 & 0.947 \\
PIGR-5 & & 0.901 & 0.901 & 0.901 & 0.947 \\
PIGR-9 & & & 1.000 & 1.000 & 0.949 \\
PIGR-13 & & & & 1.000 & 0.949 \\
PIGR-17 & & & & & 0.949 \\
PIGR-19 & & & & & \\
\hline
\end{tabular}

trols (case: $20.7 \%$ vs controls: $14.1 \%, \chi^{2}=13.05$, $P=0.00030)$. The OR for patients with IgAN versus controls was estimated to be $1.59(95 \% \mathrm{CI}=1.24-2.05)$ for the minor allele versus major allele.

The PIGR-2 SNP $(\mathrm{G} \rightarrow \mathrm{T})$ in the 5' flanking region could affect promoter activity. The frequency of the minor $\mathrm{T}$ allele at the PIGR-2 locus was significantly higher in patients with IgAN than in controls (case: $18.4 \%$ vs controls: $\left.12.4 \%, \chi^{2}=11.95, P=0.00055\right)$. The OR for patients with IgAN versus controls was 1.60 (95\% CI $=1.22-2.08)$ for the minor allele versus the major allele. Pair-wise LD between each pair of all six SNPs was calculated on the basis of case and control subjects. LD coefficients among the six SNPs indicated quasi-complete LD (D'>0.9; Table 2).

Further analysis indicated that individuals having the TT genotype (homozygotes for the minor allele) of
PIGR-17 were likely to have a higher risk of IgAN because the OR of the genotype (TT vs CC or CT) was as high as 2.71 , with a $95 \%$ CI of 1.31-5.61. We compared clinical data between patients with the TT genotype and those with the CC or CT genotypes but found no significant differences with respect to age, sex, levels of serum IgA or serum creatinine, or 24-h urinary excretion of protein at the time of renal biopsy (Table 3 ).

Finally, we performed immuohistological staining of polymeric immunoglobulin receptor in biopsy specimens in order to investigate a potential role of this molecule in the pathogenesis of $\operatorname{IgAN}$. When sections of normal colonic mucosa were used as a positive control, strong positive staining for $\mathrm{SC}$ was observed in the mucosa of the colon. Although no staining was observed in any of the glomeruli in the normal kidney, positive staining was seen for SC and IgA at the mesangial area of glomeruli in patients with IgAN (Fig. 2). When we examined immunostaining for SC on a total of nine speciemens (about three of each genotype), SC deposition were detected in all nine speciemens $(100 \%)$. However, no significant correlation for staining of SC was determined with genotyping.

\section{Discussion}

We have demonstrated here a significant association of six SNPs in the PIGR gene with IgA nephropathy. IgAN is a complex disorder whose etiology involves immuno- 
Table 3 Clinical and biological variables at the time of renal biopsy. Results are given as mean $\pm \mathrm{SD}$ ( $N S$ not significant)
Fig. 2A-D

Immunohistochemical localization of $\operatorname{IgA}$ and secretory component in biopsy specimens of patients with IgAN and control tissues obtained from patients who had undergone colectomy because of colon cancer or nephrectomy because of renal cell carcinoma. Staining for secretory component (D) was carried out on the section next to that stained for IgA (C). A Positve control: colonic mucosa. B Negative control: normal kidney. C Anti-IgA antibody. D Anti-secretory component. $\times 250$

\begin{tabular}{lllll}
\hline & All patients & PIGR-17 $(\mathrm{CC}+\mathrm{CT})$ & PIGR-17 (TT) & $P$-value \\
\hline No. of patients & 389 & 365 & 24 & \\
Age in years & $38.5 \pm 14.4$ & $37.9 \pm 14.7$ & $42.3 \pm 6.7$ & $\mathrm{NS}$ \\
Gender (M/F) & $167 / 222$ & $158 / 207$ & $9 / 15$ & $\mathrm{NS}$ \\
Serum IgA (mg/dl) & $338.6 \pm 261.9$ & $342.8 \pm 273.0$ & $346.5 \pm 156.1$ & $\mathrm{NS}$ \\
Serum creatinine $(\mathrm{mg} / \mathrm{dl})$ & $0.98 \pm 0.33$ & $0.98 \pm 0.33$ & $1.07 \pm 0.41$ & $\mathrm{NS}$ \\
24-h Proteinuria $(\mathrm{g} / \mathrm{dl})$ & $0.89 \pm 1.01$ & $0.88 \pm 1.01$ & $1.14 \pm 1.30$ & $\mathrm{NS}$ \\
\hline
\end{tabular}
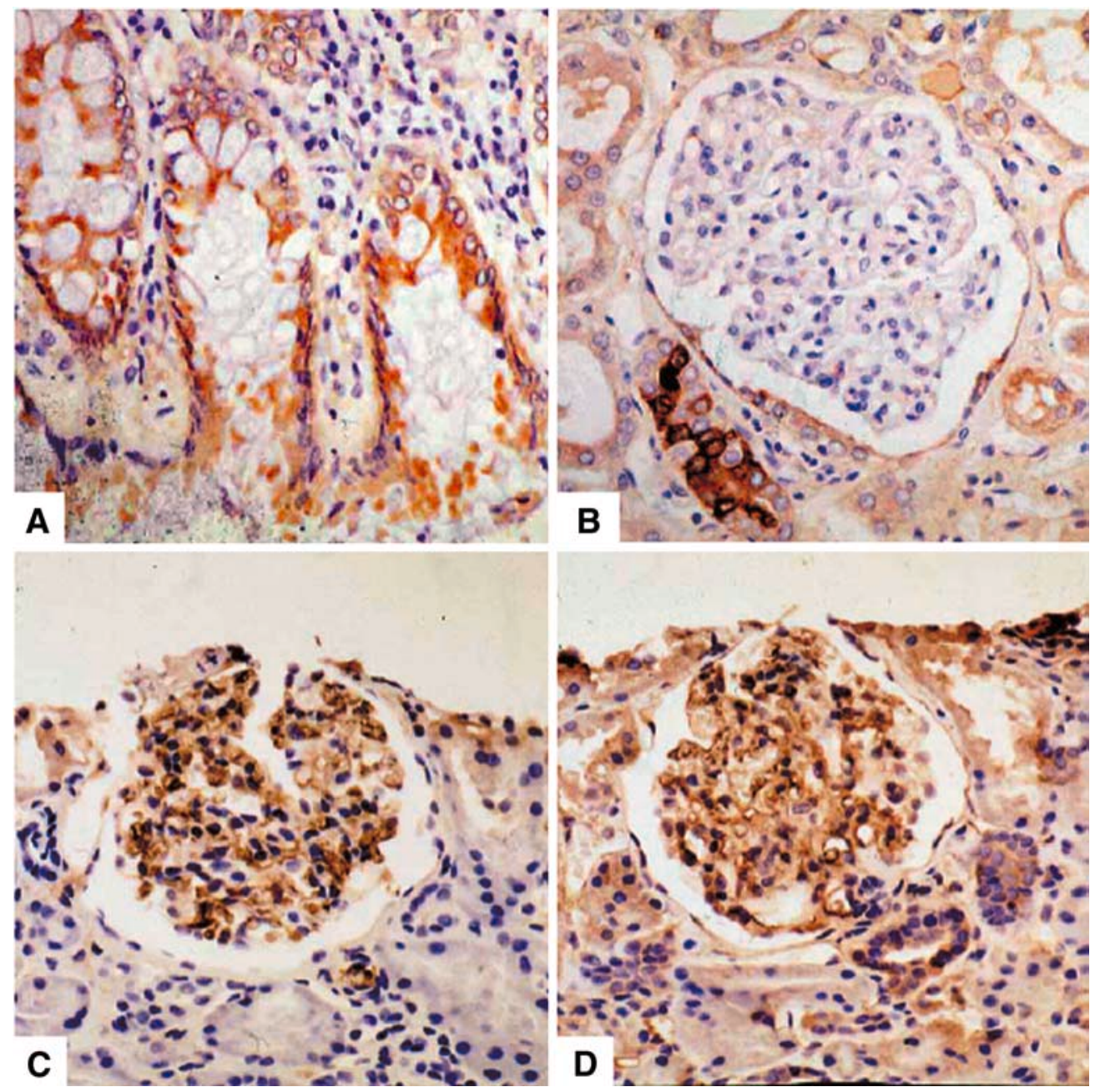

logical, environmental, and genetic factors (Hsu et al. 2000). Gharavi et al. (2000) have reported a genomewide analysis of familial cases, but the great majority of patients with IgAN have no apparent familial history. Hence, most of the genetic investigations reported to date on IgAN have been association studies that have searched for susceptibility genes in a given population. Our study is the first to report a whole-genome association study; this appears to have been an efficient approach for identifying major susceptibility genes for this disease in the Japanese population.

We found significant association between $\operatorname{IgA}$ nephropathy and homozygotes for minor alleles at six
SNP loci in the PIGR gene: PIGR-2, PIGR-5, PIGR-9, PIGR-13, PIGR-17, and PIGR-19. These showed strong LD with each other. Among them, PIGR-17, which substitutes valine for alanine at codon 580, and PIGR-2, which is located in the promoter region, are likely to influence the quality or the quantity of the gene product. Haplotype analyses for SNPs that may affect gene products often increase the significance of associations; however, since the two SNP loci in question showed only quasi-complete LD (data not shown), analyses of this particular two-locus haplotype (PIGR-2 and PIGR-17) yielded no increase of significance in comparison with our single-locus tests. 
Increases in serum IgA levels have been observed in $50 \%-70 \%$ of IgAN patients (Lopez-Trascasa et al. 1980). Elevated serum IgA, particularly when associated with mucosal infections, such as respiratory pathogens and dietary components, suggest that mucosal immunity might play a critical role in the pathogenesis of this disease (Suzuki et al. 1990). Activation of the mucosal immune system presumably increases the production of polymeric $\operatorname{IgA}(\mathrm{pIgA})$ in the bone marrow (De Fijter et al. 1996). Indeed, up-regulation of pIgA synthesis in the bone marrow and an increase of pIgA-producing plasma cells have been described in patients with IgAN (Harper et al. 1996; Van den Wall Bake et al. 1988).

$P I G R$ encodes a type I transmembrane protein with five immunoglobulin superfamily-homology domains constituting its $\mathrm{N}$-terminal extracellular region, a single membrane-spanning region, and a short cytoplasmic C-terminal tail. The extracellular ligand-binding portion (from amino acid 550 to amino acid 764 in human PIGR), known as the secretory component (SC), is proteolytically cleaved from the apical surface of epithelial cells and released together with polymeric immunoglobulins such as dimeric IgA or tetrameric IgM. Association with $\mathrm{SC}$ is believed to protect IgA from degradation by bacterial proteases (Kilian et al. 1983). In the present study, we found a significant increase in the frequency of valine alleles at codon 580 in IgAN patients and assume that 580V-PIGR affects the binding of pIgA-PIGR, decreases the cleavage and production of SC, and then elevates the serum IgA level. However, since we discerned no relationship between this polymorphism and serum IgA levels, we speculate that the mechanism of serum IgA elevation in $\operatorname{IgAN}$ patients is likely to be complex and cannot be explained by the alteration of a single factor.

Although functional studies with biochemical and cellular-biological techniques will be required to clarify the relationship between the genetic variations reported here and $\operatorname{IgAN}$, the results of our genetic investigation suggest that an allele conferring susceptibility to this disease lies within or close to the PIGR locus on chromosome 1q31-41.

Acknowledgements We gratefully acknowledge assistance from Susumu Saito, Akihiro Sekine, and technicians at the SNP Research Center, The Institute of Physical and Chemical Research (RIKEN). This work was supported in part by a "Research for the Future" Program Grant of the Japan Society for the Promotion of Science to Y.N.

\section{References}

Akiyama F, Tanaka T, Yamada R, Ohnishi Y, Tsunoda T, Maeda S, Takei T, Obara W, Ito K, Honda K, Uchida K, Tsuchiya K, Nitta K, Yumura W, Nihei H, Ujiie T, Nagane Y, Miyano S, Suzuki Y, Fujioka T, Narita I, Gejyo F, Nakamura Y (2002) Single-nucleotide polymorphisms in the class II region of the major histocompatibility complex in Japanese patients with immunoglobulin A nephropathy. J Hum Genet 47:532-538

Berger J, Hinglasis N (1968) Les depots intracapillaries d'IgA-IgG. J Urol Nephrol 74:694-695
Brandtzaeg P, Prydz H (1984) Direct evidence for an integrated function of $\mathbf{J}$ chain and secretory component in epithelial transport of immunoglobulins. Nature 311:71-73

De Fijter, Eijgenraam JW, Braam CA, Holmgren J DM, Es LA van, Van den Wall Bake AWL (1996) Deficient IgA1 immune response to nasal cholera toxin subunit $\mathrm{B}$ in primary $\operatorname{IgA}$ nephropathy. Kidney Int 50:952-961

Devlin B, Risch N (1995) A comparison of linkage disequilibrium measures for fine-scale mapping. Genomics 29:311-322

Gharavi AG, Yan Y, Scolari F, Schena FP, Frasca GM, Ghiggeri GM, Cooper K, Amoroso A, Viola BF, Battini G, Caridi G, Canova C, Farhi A, Subramanian V, Nelson-Williams C, Woodford S, Julian BA, Wyatt RJ, Lifton RP (2000) IgA nephropathy, the most common cause of glomerulonephritis, is linked to 6q22-23. Nat Genet 26:354-357

Harper SJ, Allen AC, Pringle JH, Feehally J (1996) Increased dimeric $\operatorname{Ig}$ A producing $\mathrm{B}$ cells in the bone marrow in $\operatorname{IgA}$ nephropathy determined by in situ hybridisation. J Clin Pathol 49:38-42

Hsu SIH, Ramirez SB, Winn MP, Bonventre JV, Owen WF (2000) Evidence for genetic factors in the development and progression of IgA nephropathy. Kidney Int 57:1818-1835

Iida A, Saito S, Sekine A, Mishima C, Kondo K, Kitamura Y, Harigae S, Osawa S, Nakamura Y (2001) Catalog of 258 singlenucleotide polymorphisms (SNPs) in genes encoding three organic anion transporters, three organic anion-transporting polypeptides, and three NADH: ubiquinone oxidoreductase flavoproteins. J Hum Genet 46:668-683

Kilian M, Reinholdt J, Mortensen SB, Sorensen CH (1983) Perturbation of mucosal immune defence mechanisms by bacterial IgA proteases. Bull Eur Physiopathol Respir 19:99104

Koyama A, Igarashi M, Kobayashi M, Members and Coworkers of the Research Group on Progressive Renal Diseases (1997) Natural history and risk factors for immunoglobulin A nephropathy in Japan. Am J Kidney Dis 29:526-532

Krajci P, Solberg R, Sandberg M, Oyen O, Jahnsen T, Brandtzaeg $\mathrm{P}$ (1989) Molecular cloning of the human transmembrane secretory component (poly-Ig receptor) and its mRNA expression in human tissues. Biochem Biophys Res Commun 158:783789

Kruglyak L (1999) Prospects for whole-genome linkage disequilibrium mapping of common disease genes. Nat Genet 22:139 144

Lander E, Kruglyak L (1995) Genetic dissection of complex traits: guidelines for interpreting and reporting linkage results. Nat Genet 11:241-247

Lopez-Trascasa M, Egido J, Hernando L (1980) IgA glomerulonephritis (Berger's disease). Evidence of high serum levels of polymeric IgA. Clin Exp Immunol 42:247-254

Mein CA, Barratt BJ, Dunn MG, Siegmund T, Smith AN, Esposito L, Nutland S, Stevens HE, Wilson AJ, Phillips MS, Jarvis N, Law S, Arruda M de, Todd JA (2000) Evaluation of single nucleotide polymorphism typing with Invader on PCR amplicons and its automation. Genome Res 10:330-343

Mostov KE, Friedlander M, Blobel G (1984) The receptor for transepithelial transport of $\operatorname{IgA}$ and $\operatorname{IgM}$ contains multiple immunoglobulin-like domains. Nature 308:37-43

Nielsen DM, Ehm MG, Weir BS (1998) Detecting marker-disease association by testing for Hardy-Weinberg disequilibrium at a marker locus. Am J Hum Genet 63:1531-1540

Ohnishi Y, Tanaka T, Ozaki K, Yamada R, Nakamura Y (2001) A high-throughput SNP typing system for genome-wide association studies. J Hum Genet 46:471-477

Schena FP (1998) Immunogenetic aspects of primary IgA nephropathy-Nephrology Forum. Kidney Int 48:1998-2013

Shimada S, Kawaguchi-Miyashita M, Kushiro A, Sato T, Nanno M, Sako T, Matsuoka Y, Sudo K, Tagawa Y, Iwakura Y, Ohwaki M (1999) Generation of polymeric immunoglobulin receptor-deficient mouse with marked reduction of secretory IgA. J Immunol 163:5367-5373 
Suzuki S, Kobayashi H, Sato H, Arakawa M (1990) Immunohistochemical characterization of glomerular IgA deposits in IgA nephropathy. Clin Nephrol 33:66-71

Takei T, Iida A, Nitta K, Tanaka T, Ohnishi Y, Yamada R, Maeda S, Tsunoda T, Takeoka S, Ito K, Honda K, Uchida K, Tsuchiya K, Suzuki Y, Fujioka T, Ujiie T, Nagane Y, Miyano S, Narita I, Gejyo F, Nihei H, Nakamura Y (2002) Association between single-nucleotide polymorphisms in selectin genes and immunoglobulin A nephropathy. Am J Hum Genet 70:781-786

Van den Wall Bake AWL, Daha MR, Evers-Schouten J, Es LA van (1988) Serum IgA and production of IgA by peripheral blood and bone marrow lymphocytes in patients with primary IgA nephropathy. Evidence for the bone marrow as a source of mesangial IgA. Am J Kidney Dis 12:410-414 